\title{
Fases para el diseño y análisis de la Cadena de Valor en las organizaciones
}

\author{
Emilio García Vega \\ MBA y Licenciado en Administración por la Universidad del Pacífico, Lima, Perú. \\ Profesor e investigador de Estrategia Empresarial y Marketing del Departamento Académico de Adminis- \\ tración de la Universidad del Pacífico, Lima, Perú.
}

\section{Resumen}

La generación de valor es un tema fundamental en la gestión de las organizaciones debido a que permite la satisfacción de los consumidores, la dinámica frente a la competencia y la retribución a los dueños o accionistas. Su tratamiento responde tanto al mundo académico como al empresarial; es decir, a docentes, investigadores, ejecutivos y responsables de las empresas, ya sean estas micro, pequeñas, medianas 0 grandes. Si bien existen diferentes aproximaciones al tema, este trabajo buscará desarrollar un acercamiento desde el punto de vista competitivo y mediante la cadena de valor, debido a que esta puede ser considerada como una herramienta válida para diseñar y analizar cómo las organizaciones generan valor. Asimismo, esta investigación trata de presentar la evolución de la generación de valor, partiendo de los modelos clásicos de McKinsey \& Company y de Michael Porter. Luego, se presentan algunos planteamientos y aportes a la cadena de valor de diferentes autores y desde diversos puntos de vista, hasta tener cercanía a la actualidad, de modo que se pueda contar con una serie de ideas adicionales, las cuales el autor considera relevantes para afrontar el diseño y análisis de la mencionada cadena. Finalmente, sobre la base del aporte capital del citado profesor de la Universidad de Harvard, se presenta una serie de recomendaciones para la aplicación estratégica de la cadena de valor en la gestión de las organizaciones actuales, las cuales están organizadas en nueve fases (fases para el diseño y análisis de la cadena de valor).

Palabras clave: Generación de valor, cadena de valor, análisis interno, análisis estratégico, estrategia empresarial.

\section{Introducción}

En el ámbito del Management, la generación de valor es un tema de preocupación constante y estratégico para los administradores de empresas o de cualquier tipo de organizaciones. Darle al cliente la satisfacción -a partir de proporcionarle una sensación de «bienestar o deleite»-, que demanda mediante productos y servicios, es la génesis y fundamento de la actividad empre- sarial. En suma, la propuesta de valor es una de las principales preocupaciones, sino la más relevante, de ejecutivos y empresarios. Así, Porter (1987: 2-3) sostiene que:

«la ventaja competitiva nace fundamentalmente del valor que una empresa logra crear para sus clientes y que supera los costos de ello. El valor es lo que la gente está dispuesta a pagar y el valor superior se obtiene al ofrecer precios más bajos que la com- 
petencia por beneficios equivalentes o especiales que compensan con creces un precio más elevado».

\section{Además, sostiene que}

\begin{abstract}
«desde el punto de vista de la competencia, el valor es lo que la gente está dispuesta a pagar por lo que se le ofrece. El valor se mide por los ingresos totales, reflejo del precio que se cobra por el producto y de las unidades que logra vender. Una empresa es rentable si su valor rebasa los costos de crear un producto» (1987: 36).
\end{abstract}

Tratar el tema de la generación de valor implica involucrar a muchos agentes y analizarlo desde diversas aristas. Así, se tiene el valor que se genera para los accionistas, para los clientes o compradores, para los consumidores, para los clientes internos, frente a la competencia, entre otros. Para tener cierto acercamiento al tema, se realizaron entrevistas con un grupo de ejecutivos, a los cuales se les preguntó acerca del significado de la generación de valor. Así, la mayoría afirmó que el valor hacía referencia a la satisfacción de los accionistas, de los clientes y del personal interno de la empresa -en ese orden-; sin embargo, un pequeño grupo afirmó que el valor iba más allá de la mera organización y que implicaba a los Stakeholders ${ }^{1}$ externos involucrados ${ }^{2}$.

\section{Band (1994: 4) afirmó que}

"para salir a flote o para colocarse entre las primeras, las empresas tendrán que funcionar a partir de estrategias basadas en la flexibilidad organizacional, en un inexorable impulso para crear y entregar un verdadero valor y una constante atención a los detalles de las demandas de los consumidores».

Por otro lado, Tapscott (2000: 14) opina que «toda empresa o industria se basa en una propuesta de valor: el valor que proponen y consumen los clientes. La propuesta de valor contiene varios elementos que son tomados de los proveedores y de los empleados y suministrados a los clientes»». La literatura y la praxis de la administración le dan mucha importancia al desarrollo del valor para el cliente, lo consideran como la razón fundamental de ser de las organizaciones. Se puede afirmar que el valor genera una preferencia que impulsa la adquisición de bienes y servicios, los que devienen en los flujos financieros que permiten que las empresas sean rentables, crezcan o sobrevivan. Así, en la línea de la generación de valor para el accionista, Pérez-Carballo (1999: 73) afirma que

\footnotetext{
"la creación de valor es un concepto dinámico que exige la mejora continua de los flujos de caja previstos por medio de la implantación permanente de nuevas estrategias rentables. El concepto de creación de valor a largo plazo solo es aplicable a empresas que cuentan con esa capacidad reconocida de innovación permanente».
}

El desarrollo de la Internet es otro elemento por tomarse en cuenta en la generación de valor, debido a que revoluciona, cada vez más, las formas de hacer negocios y, por ende, los modelos relacionados. En este ámbito, Tapscott (2000: 16) afirma que

"los managers de todas las industrias -desde los servicios financieros a los distribuidores automotores- necesitan examinar sus actuales propuestas de valor o invertir más tiempo en presagiar nuevas propuestas que atraerían a los clientes. Tales propuestas pueden luego ser desintegradas y desmembradas para determinar cómo, por quién y en qué condiciones el valor puede ser reintegrado y reconfigurado a través de nuevos socios en la Red».

El presente desarrollo se centrará en la generación de valor desde el punto de vista competiti-

1. Freeman (1984) define stakeholders como cualquier individuo o grupo que puede afectar o ser afectado por la consecución de los objetivos de una organización.

2. Aproximación al tema sobre la base de respuestas de diez ejecutivos que se desempeñan en ápices estratégicos de organizaciones locales ante la interrogante: Desde el punto de vista empresarial, ¿para usted, qué significa la generación de valor? 
vo. En ese sentido, los aportes se pueden aglutinar en un modelo que es muy empleado por los administradores: el de la cadena de valor, en el cual destaca el planteamiento de M. Porter en el año 1985, como eje básico del tema. Sin embargo, tanto el mismo autor como una gran variedad de teóricos de diversa envergadura, han planteado aportes adicionales o complementarios con respecto al tema.

En suma, el concepto de generación de valor se ha ido complementado de manera progresiva en más de dos décadas de desarrollos.

\section{Objetivos}

Antes de presentar los objetivos de este trabajo de investigación, se quiere expresar con claridad que este documento no pretende criticar ni tachar algún planteamiento o teoría desarrollada por autores de diversas envergaduras académicas, procedencias, prestigios, formaciones y edades. Lo que se pretende simplemente es brindar elementos para que académicos y ejecutivos tengan un panorama amplio de los diversos desarrollos en la generación de valor y su evolución. Además, se plantean algunas recomendaciones al respecto. Luego de realizada esta aclaración, se presentan los objetivos de esta investigación.

\section{Objetivo principal}

- Plantear recomendaciones para el diseño y análisis de la cadena de valor sobre la base de planteamientos que complementen los enfoques clásicos al respecto.

\section{Objetivos secundarios}

- Generar un acercamiento a la evolución del tema de generación de valor por parte de las organizaciones.

- Conocer planteamientos complementarios a la generación de valor en las organizaciones.

- Tener elementos para facilitar el diseño y análisis de la cadena de valor en las organizaciones.
- Lograr un acercamiento a los avances de los enfoques administrativos en el tema de la generación de valor.

\section{Metodología}

Para el desarrollo de esta investigación, se siguió la siguiente metodología:

- Una revisión bibliográfica de los desarrollos clásicos en el tema de generación de valor. Así, se recurrió a las fuentes fundacionales en el tema; es decir, a los desarrollos de la consultora McKinsey y al concepto de cadena de valor del reputado profesor de estrategia empresarial de la Universidad de Harvard, Michael Porter.

- Luego, se continuó la revisión bibliográfica con el fin de identificar otros desarrollos de la cadena de valor que pueden resultar relevantes para los objetivos de la investigación.

- Seguidamente, la revisión trató de identificar planteamientos interesantes en el tema de generación de valor, tanto para el diseño de la cadena de valor como para su análisis, tratando de llegar hasta la actualidad.

- Con toda la información identificada se procedió a diseñar una agrupación o sistematización, la cual consta de las siguientes partes:

- Modelos básicos para el diseño y comprensión de la generación de valor. Concentran los desarrollos fundacionales y fundamentales en el tema de cadena de valor.

- Desarrollos por tenerse en cuenta en la adaptación-diseño de la cadena de valor. En esta parte se sugieren algunos elementos que un administrador puede tener como referencia para la adecuación de los modelos básicos de la cadena de valor a su organización.

- Lógicas estratégicas por considerar en el diseño y análisis de la cadena de valor. Se presentan desarrollos que pueden ampliar el enfoque y pensamiento estratégicos de los administradores en el proceso de diseño y análisis de la cadena de valor. 
- Modelos e ideas por tenerse en cuenta para el análisis y evaluación de la cadena de valor. Se plantean elementos que se pueden tener presentes en el mencionado análisis.

- Finalmente, sobre la base de los aportes y elementos identificados, se procedió a la formulación de una serie de recomendaciones que se agrupan en nueve fases. Estas tratarán de cubrir el diseño y análisis de la cadena de valor; además de sugerir ideas para el desarrollo de los ajustes -o replanteamientos radicalesnecesarios, tratando de pensar tanto en el presente organizacional como en su futuro.

\section{Marco conceptual: el diseño y el análisis de la generación de valor}

Las organizaciones se alimentan del entorno, la industria y de sí mismas para su generación y propuesta de valor. Un modelo para desarrollar dicha proposición es la cadena de valor. Michael Porter (1987: 36) afirma que:

«la empresa es un conjunto de actividades cuyo fin es diseñar, fabricar, comercializar, entregar y apoyar su producto. Se puede representarla por medio de la Cadena de Valor (...). La Cadena de Valor y la forma en que realiza las actividades individuales reflejan su historial, su estrategia, su enfoque en el establecimiento de la estrategia y la economía en la que se basan dichas actividades»»

En esta línea, la cadena de valor «desagrega a la empresa en una cadena de actividades secuenciales»(Grant 1996: 167).

\section{La cadena de valor de McKinsey \& Company}

En el año de 1980, McKinsey \& Company plantea un modelo que buscó desagregar a la empresa en una cadena de actividades secuenciales construida sobre el concepto de «sistema de negocios» (Guitart 2005: 10-11). Es un concepto que pone en evidencia el hecho de que todos los negocios son una cadena de actividades que van desde la entrada de insumos, materias primas, entre otros, por medio de compras u otros procesos, hasta el servicio posventa. Cada eslabón debe desempeñar un papel en la contribución de la explotación de las fuentes potenciales de ventajas competitivas sobre los competidores (Manso 2003: 55). En el gráfico 1 se puede observar un esquema de ese planteamiento.

Este planteamiento es el primigenio en el desarrollo del concepto de la cadena de valor y de los modelos relacionados con ella.

\section{Gráfico 1}

\section{La cadena de valor de McKinsey \& Company: «el sistema de negocios»}

\begin{tabular}{|lllllll|}
\hline TECNOLOGÍA & $\begin{array}{l}\text { DISEÑO DEL } \\
\text { PRODUCTO }\end{array}$ & FABRICACIÓN & DISTRIBUCIÓN & SERVICIO \\
Fuente & Función & Integración & Precios & Canales & Garantía \\
Sofisticación & Características & Materias primas & Publicidad / & Integración & Plazo \\
Patentes & Físicas & Capacidad & Promoción & Inventario & Cautivo / \\
Elección & Estética & Localización & Fuerza de ventas & Almacenaje & Independiente \\
Producto/proceso & Calidad & Aprovisionamiento & Empaquetado & Transporte & Precios \\
& & Producción de & Marca & & \\
& piezas & & &
\end{tabular}

Fuente: Grant 1996: 167 


\section{La cadena de valor de Michael Porter ${ }^{3}$}

Michael Porter define la cadena de valor como la herramienta básica para analizar las fuentes de la ventaja competitiva de una empresa, ya que es un medio sistemático que examina todas las actividades que realiza la empresa y su manera de interactuar (Porter 1985). Esta herramienta permite dividir la compañía en función de sus actividades, con la finalidad de entender el comportamiento de los costos, así como las fuentes actuales y potenciales de diferenciación. No se puede entender la ventaja competitiva de una empresa si se examina la empresa en su conjunto, ya que la ventaja nace de cada una de las actividades que la empresa ejecuta al diseñar, fabricar, comercializar, entregar y apoyar su producto. Asimismo, el autor define al valor como la suma de los beneficios percibidos que el cliente recibe menos los costos percibidos por él, al adquirir y usar un producto o servicio ${ }^{4}$.

Porter afirma que las diferencias entre las cadenas de valor de las diversas empresas que compiten en una industria, reflejan su desarrollo histórico, sus estrategias y sus éxitos organizacionales. Las divergencias con las de la competencia pueden representar una fuente potencial de ventaja competitiva. Por otro lado, el hecho de atender solo a un segmento de la industria permite adaptar la cadena de valor a él, reduciéndose así los costos o diferenciándose de la competencia. En la ventaja competitiva también influye la ampliación o reducción de los mercados geográficos, al igual que el grado de integración de las actividades. Una firma puede aprovechar internamente los beneficios de un alcance mayor o formar para ello coaliciones con otras empresas (requiere coordinar o compartir cadenas de valor).

Cabe resaltar que, a pesar de que dos empresas puedan pertenecer a la misma industria, no ne- cesariamente tendrán las mismas cadenas de valor. Entre estas siempre existirán pequeñas diferencias en sus operaciones, de las cuales se puede originar una ventaja competitiva (diferencias en operaciones que se reflejarán en variaciones de las cadenas de valor).

Porter sostiene que la cadena de valor contiene las actividades físicas y tecnológicas que se llevan a cabo para crear un producto para los compradores. Plantea que en las cadenas de valor de las organizaciones, se puede distinguir entre actividades de margen y actividades de valor. El margen es la diferencia entre el valor total y el costo colectivo de efectuar las operaciones. Toda actividad de valor utiliza insumos adquiridos, recursos humanos y tecnología. También usa y genera información, y puede generar activos financieros (inventarios y cuentas por cobrar) o pasivos (cuentas por pagar). Las actividades de valor se dividen en dos grandes grupos: primarias y de apoyo.

- Las primarias son las que intervienen en la creación física del producto, en su venta y transferencia al cliente, así como en la asistencia posterior a la venta.

- Las actividades de apoyo respaldan a las primarias y viceversa, al ofrecer insumos, tecnología, recursos humanos y diversas funciones globales.

La forma en que se realizan estas actividades de valores, junto con su economía, determinarán si una firma tiene costos altos o bajos frente a la competencia. Las diferencias que rigen la ventaja competitiva quedan al descubierto cuando se comparan las cadenas de valores de los rivales. La forma adecuada de examinar la ventaja competitiva consiste en analizar la cadena de valor y no el valor agregado (precio de venta menos costo de materias primas), pues el valor agregado no es un criterio sólido en vista de que distingue de

3. Porter (1987: 33-59).

4. Cabe mencionar que en una nota a pie de página, Porter (2006: 36) hace referencia a la cadena de valor de McKinsey: «(...) El concepto de sistema de negocios se centra en funciones generales más que en actividades, sin que distinga los tipos de ellas ni muestre cómo se relacionan. No está ligado concretamente a la ventaja competitiva ni al alcance competitivo. (...)». 
manera incorrecta las materias primas e insumos para las actividades de la organización. Aun más, el valor agregado no pone de relieve los nexos entre una firma y sus proveedores, los cuales pueden reducir el costo o mejorar la diferenciación.
En el cuadro 1 se presenta la identificación y clasificación de las actividades relacionadas con la generación de valor. Cabe mencionar que cada actividad puede dividirse en subactividades que dependen de la industria y de la estrategia de la corporación.

\section{Cuadro 1}

Identificación de las actividades relacionadas con valores: Actividades relacionadas con la generación de valor según Michael Porter

\begin{tabular}{|c|c|c|c|}
\hline \multicolumn{2}{|r|}{ ACTIVIDADES PRIMARIAS } & \multicolumn{2}{|c|}{ ACTIVIDADES DE APOYO A LOS VALORES } \\
\hline $\begin{array}{l}\text { Logística de } \\
\text { entrada }\end{array}$ & $\begin{array}{l}\text { Actividades relacionadas con la recep- } \\
\text { ción, el almacenamiento y la distribu- } \\
\text { ción de los insumos del producto. }\end{array}$ & Adquisición & $\begin{array}{l}\text { Función de comprar los insumos que se } \\
\text { emplearán en la cadena de valor. }\end{array}$ \\
\hline Operaciones & $\begin{array}{l}\text { Actividades por las que se transforman } \\
\text { los insumos en productos finales. }\end{array}$ & $\begin{array}{l}\text { Desarrollo } \\
\text { tecnológico }\end{array}$ & $\begin{array}{l}\text { Toda actividad relacionada con valores } \\
\text { comprende la tecnología, los procedi- } \\
\text { mientos prácticos, los métodos o la tec- } \\
\text { nología integrada al equipo de proce- } \\
\text { sos. El desarrollo tecnológico es impor- } \\
\text { tante para la ventaja competitiva en to- } \\
\text { das las industrias, siendo el elemento } \\
\text { clave en algunas. }\end{array}$ \\
\hline $\begin{array}{l}\text { Logística de } \\
\text { salida }\end{array}$ & $\begin{array}{l}\text { Actividades por las que se obtiene, al- } \\
\text { macena y distribuye el producto entre } \\
\text { los clientes. }\end{array}$ & $\begin{array}{l}\text { Administración } \\
\text { de recursos } \\
\text { humanos }\end{array}$ & $\begin{array}{l}\text { Constituida por actividades como el re- } \\
\text { clutamiento, la contratación, la capacita- } \\
\text { ción, el desarrollo y la compensación de } \\
\text { todo tipo de personal. }\end{array}$ \\
\hline $\begin{array}{l}\text { Mercadotecnia } \\
\text { y ventas }\end{array}$ & $\begin{array}{l}\text { Actividades para lograr que al clien- } \\
\text { te adquiera los productos de la em- } \\
\text { presa. }\end{array}$ & $\begin{array}{l}\text { Infraestructura } \\
\text { organizacional }\end{array}$ & $\begin{array}{l}\text { Aquí se consignan actividades como la ad- } \\
\text { ministración general, planeación, finan- } \\
\text { zas, contabilidad, administración de as- }\end{array}$ \\
\hline Servicio & $\begin{array}{l}\text { Actividades que ayudan a mejorar o } \\
\text { conservar el valor del producto. }\end{array}$ & & $\begin{array}{l}\text { la organización y administración de } \\
\text { calidad.Alguna actividad de la infraestruc- } \\
\text { tura puede constituir una fuente muy im- } \\
\text { portante de ventaja competitiva. }\end{array}$ \\
\hline
\end{tabular}

Las actividades primarias son indispensables para lograr la ventaja competitiva en las diversas industrias.

En cualquier firma, las categorías de actividades primarias estarán presentes en cierto modo en ella.

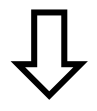

\section{TIPOS DE ACTIVIDAD}

Dentro de cada categoría de actividades primarias y de apoyo hay tres tipos que afectan a la ventaja competitiva de manera distinta: directas, indirectas o de aseguramiento de la calidad.

\begin{tabular}{|c|c|c|}
\hline Actividades directas & Actividades indirectas & Aseguramiento de la calidad \\
\hline $\begin{array}{l}\text { Intervienen directamente en la } \\
\text { creación de valor para el com- } \\
\text { prador. Porter sugiere: ensambla- } \\
\text { je, maquinado de partes, opera- } \\
\text { ción de la fuerza de ventas, pu- } \\
\text { blicidad, diseño del producto, re- } \\
\text { clutamiento, entre otras. }\end{array}$ & $\begin{array}{l}\text { Permiten efectuar actividades directas en } \\
\text { forma continua. Porter da como ejemplo } \\
\text { a: mantenimiento, programación, opera- } \\
\text { ción de instalaciones, administración de } \\
\text { la fuerza de ventas, administración de la } \\
\text { investigación, mantenimiento de registros } \\
\text { por parte de los proveedores. }\end{array}$ & $\begin{array}{l}\text { Garantiza la calidad de otras } \\
\text { actividades. Porter cita a: super- } \\
\text { visión, inspección, realización } \\
\text { de pruebas, evaluación, verifi- } \\
\text { cación, ajuste, entre otros. }\end{array}$ \\
\hline
\end{tabular}

Elaboración propia sobre la base de Porter (1987) 
Porter afirma que para diagnosticar la ventaja competitiva de una organización, es necesario definir una cadena de valor de la empresa que le permita competir. Con ella se efectúan separaciones cada vez más sutiles de algunas actividades, a medida que el análisis descubre las diferencias importantes para la ventaja competitiva; otras actividades se combinan porque no inciden en la ventaja competitiva o porque están regidas por una economía semejante. Las actividades de valor deberían asignarse a las categorías que mejor representan su aporte a la ventaja competitiva.

El autor sostiene que las actividades relacionadas con los valores son las estructuras básicas de la ventaja competitiva; sin embargo, la cadena de valor no es un conjunto de actividades independientes sino un sistema de actividades interdependientes, y se relacionan por medio de «nexos de la cadena». Un nexo es una relación entre la forma de ejecutar una actividad y el costo o desempeño de otra. Los nexos pueden originar una ventaja competitiva en dos formas: mediante la optimización y la coordinación. Los nexos entre las actividades de valor provienen de varias causas generales, entre las cuales figuran las siguientes:

1) Una misma función puede efectuarse en diversas formas.

2) El costo o la realización de actividades directas mejora poniendo mayor empeño en las actividades indirectas.

3) Las actividades realizadas dentro de la organización atenúan la necesidad de demostrar, explicar o dar mantenimiento a un producto en el campo.

4) Las funciones de aseguramiento de la calidad pueden llevarse a cabo en varias formas.

Aunque los nexos de la cadena de valor son esenciales para la ventaja competitiva, muchas veces son sutiles y pasan inadvertidos. Identificar los nexos es un proceso de búsqueda de cómo una actividad de valor afecta a otras o es afectada por ellas. Ante la dificultad de reconocer los nexos y administrarlos, la capacidad de hacerlo es a menudo una fuente sustentable de ventaja competitiva.
Luego del planteamiento de Porter, que muchos expertos considera como fundamental para la administración estratégica como disciplina, se desarrollaron otros aportes sobre la base de la lógica del autor. El modelo de cadena de valor de Porter es genérico y, a pesar de que él mismo sugiere la particularización de su cadena según la organización que se analice o trabaje, algunos expertos encasillaron dicho aporte al mundo de las organizaciones enfocadas a la manufactura. Así, algunos autores, como Heskett, Sasser y Schlesinger (1997), tuvieron la iniciativa de diseñar una cadena de valor orientada específicamente a las organizaciones que se desarrollan dentro del rubro de servicios; es decir, con un alto contacto de los empleados con los clientes y /o compradores finales.

La cadena de valor de servicios de Heskett, Loveman, Sasser y Schlesinger

Heskett, Sasser y Schlesinger (1997) afirmaron que los empleados motivados, leales y productivos transmiten valor a los clientes, quienes lo demuestran transformándose en compradores y/ o clientes leales. Esto se refleja directamente en los resultados financieros de la compañía. Los autores afirman que una de las claves más importantes para explicar el éxito de las empresas es la calidad de sus servicios y la orientación al cumplimiento de los deseos de sus clientes. Sostienen que la estrategia orientada a ello se basa principalmente en: 1) Definir sus clientes, 2) Conocer sus deseos y 3) Cumplirlos. Es el capital humano de la empresa el que se encarga de que esta estrategia realmente se traduzca en una calidad superior del servicio y en valor añadido para el cliente.

El concepto parte de la base de que el éxito en los servicios se fundamenta en la fidelidad del cliente, que implica un aumento de los beneficios y una mejora de la rentabilidad de la organización. Para que un cliente sea fiel es necesario que esté satisfecho; por lo tanto, el valor que perciba del servicio recibido tiene que ser elevado. Esta percepción es subjetiva y depende de 
las expectativas previas que tiene el cliente. El valor de un servicio es producido por los empleados y para que sea de alto valor, es necesario que estos también alcancen elevados grados de satisfacción, aspecto que depende de la calidad del entorno de trabajo y la calidad interna, que incluye conocimiento del producto y del cliente, y soporte tecnológico y personal para desempeñar el trabajo (Heskett et al. 1994: 105-111). Estas ideas se pueden resumir en el gráfico 2 .

En el esquema del gráfico 2 pueden observarse grandes actividades (en letras mayúsculas) y otras detalladas (en minúsculas). Los autores plantean que del manejo estratégico de ambas, se puede llegar a apuntar a la excelencia en el servicio.

Actualización del modelo de cadena de valor; Internet y la cadena de valor ${ }^{5}$

Porter (2001) plantea que la herramienta básica para evaluar la influencia de las tecnologías de la información (IT, por sus siglas en inglés) en las compañías es la cadena de valor. Operar una fuerza de ventas, fabricar un componente y entregar el producto son actividades creadoras de valor, y tienen puntos de conexión con las que desarroIlan proveedores, canales de distribución y los clientes. La cadena de valor permite identificarlas, y analizar su impacto en los costos y en el valor que perciben los compradores.

El autor asevera que la Internet tiene una capacidad especial de vincular actividades y, además, pone ampliamente a disposición la información en tiempo real. Su uso en las organizaciones puede hacer que la cadena de valor tenga actividades en línea (online) y que, además, otras pueden tornarse más eficientes en términos de costos.

Porter afirma que a pesar de su poder, Internet no constituye un quiebre con el pasado, sino la más reciente etapa evolutiva de las IT. Las posibilidades tecnológicas actuales no derivan solo de la arquitectura de Internet, sino de avances tecnológicos complementarios (escaneo, programación

\section{Gráfico 2}

\section{Cadena de valor de los servicios (Heskett, Sasser y Schlesinger)}

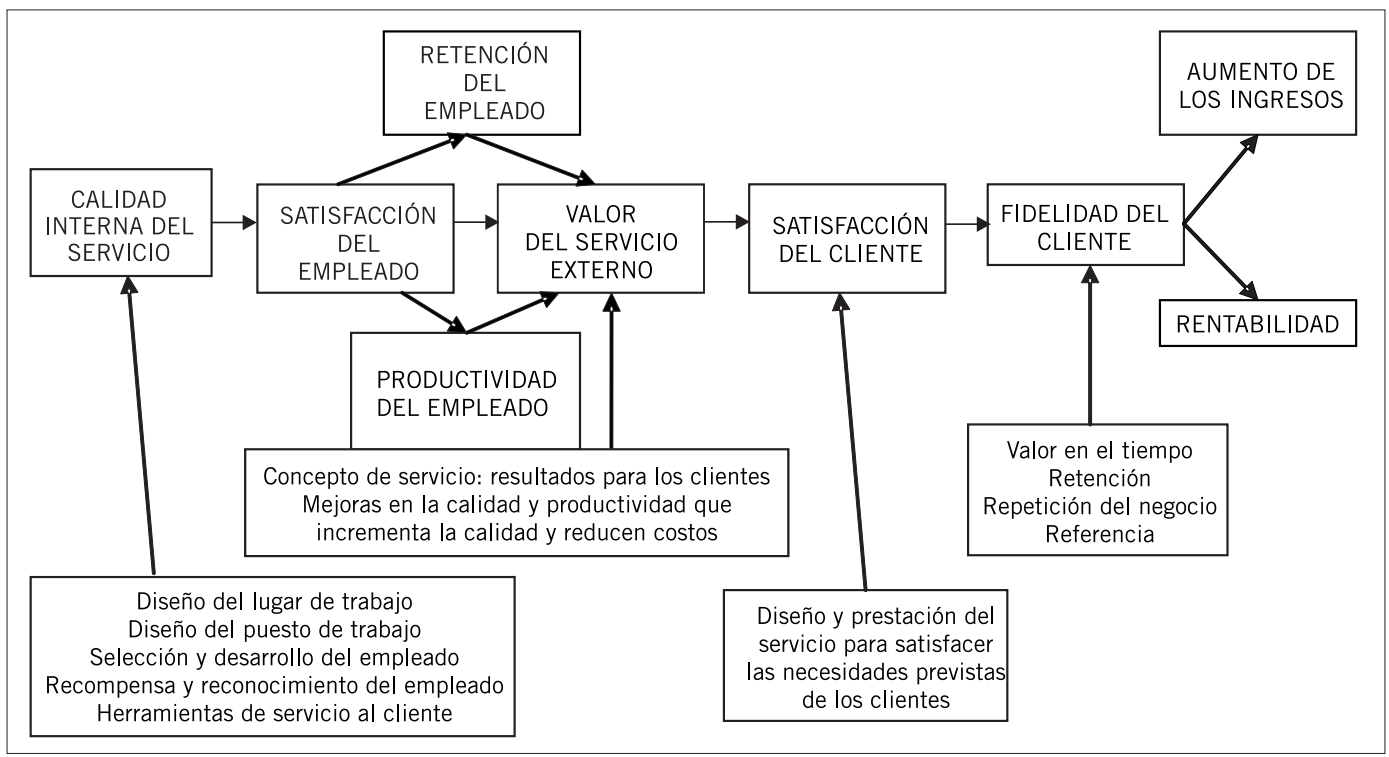

Fuente: Heskett et al. 1994

5. Porter (2001: 62-78) 
orientada al objeto, bases de datos relacionales y comunicaciones inalámbricas). Las distintas actividades se conectan mediante herramientas como CRM (Gestión de Relaciones con el Cliente), SCM (Administración de la Cadena de Abastecimiento) y ERP (Planificación de Recursos de la Empresa). La actual etapa de la IT Ileva a la integración de todo el sistema de valor; es decir, del conjunto de cadenas de valor de toda una industria, abarcando a proveedores, canales y clientes. Esta no se utilizará solo para conectar actividades y jugadores dentro del sistema de valor, sino también para optimizar sus operaciones en tiempo real.

Con este planteamiento, el autor incluye a la Internet-considerado por muchos expertos como la innovación más importante de los últimos treinta años ${ }^{6}$ - en su modelo de cadena de valor, como un elemento dinamizador y facilitador dentro de la generación de valor de una organización.

\section{La «nueva» cadena de valor ${ }^{7}$}

Briz y Lazo (2001) plantean que la Internet puede mejorar, empeorar o plantear "saltarse» algunos de los eslabones clásicos del modelo de Porter. Afirman que dos son los aportes básicos a la cadena de valor, los cuales están aunados a la traslación de poder hacia los consumidores:

1) La separación de los eslabones clásicos de la cadena, y sugieren incluir la generación de contenidos y una distribución especial debido a la naturaleza de la Internet.

2) Una mayor generación de valor, ya que las páginas web permiten una comunicación más cercana con los consumidores y una experiencia mayor por medio de servicios adicionales que se les puede ofrecer.

Planteamientos adicionales para la generación del valor en las organizaciones: ideas por tener en cuenta en el diseño y análisis de la cadena de valor a finales de la primera década del siglo XXI
A continuación se citan algunos planteamientos adicionales desarrollados en los últimos años y que, a juicio del autor, se pueden considerar como relevantes e interesantes para la generación de valor de las organizaciones y que pueden complementar el diseño y análisis de la cadena de valor.

- La lógica de la innovación de valor frente a lógica convencional ${ }^{8}$

Mauborgne y Chan (1997) se preocuparon por desarrollar una investigación acerca de las razones por las cuales unas organizaciones pueden mantener un alto crecimiento y otras no lo lograban. Luego de realizar una investigación en un número razonable de organizaciones, llegaron a la conclusión que las que lograban rendimientos superiores son aquellas que tratan de hacer que sus competidores sean «irrelevantes». Los mencionados autores denominaron «innovación de valor» al mecanismo por el cual este tipo de compañías lograron dichos resultados.

En este planteamiento se puede apreciar el inicio del concepto de "Estrategia del océano azul» - Blue Ocean Strategy (encontrar mercados no disputados en los cuales las empresas evitan la competencia descarnada y crean nuevos espacios de desarrollo para sus productos y servicios), acuñado en un artículo del año $2004^{9}$, el cual fue ampliado en un libro que vio la luz editorial en el siguiente año (Chan y Mauborgne 2005).

Los autores sostienen que la estrategia empresarial tienen cinco dimensiones: 1) Los supuestos de la industria, 2) El enfoque estratégico, 3) Los clientes, 4) Los activos y las capacidades, y 5) La oferta de productos y servicios. Sobre la base de estas cinco estrategias, proponen una nueva forma de lógica estratégica («lógica de la innovación en valor») en detrimento de una antigua («lógica convencional»). En el cuadro 2, se presenta un resumen de este desarrollo.

6. Un alcance al respecto se puede revisar en <http://www.pbs.org/nbr/site/features/special/top-30-innovations_home/>.

7. Briz y Lazo (2001: 93-95)

8. Mauborgne y Chan (1997: 103-112).

9. Chan, W. y R. Mauborgne (2004). «Blue Ocean Strategy». En: Harvard Business Review, octubre, pp. 76-85. 


\section{Cuadro 2}

\section{La lógica convencional y la lógica de la innovación de valor}

\begin{tabular}{|c|c|c|c|}
\hline \multicolumn{2}{|c|}{ Dimensiones de la estrategia } & \multirow{2}{*}{$\begin{array}{l}\text { La lógica convencional } \\
\text { Las condiciones de la indus- } \\
\text { tria están dadas }\end{array}$} & \multirow{2}{*}{$\begin{array}{l}\text { La lógica de la } \\
\text { innovación en valor } \\
\text { Las condiciones de la industria } \\
\text { no son limitantes. }\end{array}$} \\
\hline $\begin{array}{l}\text { 1. Supuestos } \\
\text { de Industria }\end{array}$ & $\begin{array}{l}\text { Muchas empresas toman las } \\
\text { condiciones de su industria } \\
\text { como un hecho. En conse- } \\
\text { cuencia, establecen su estra- } \\
\text { tegia sobre la base de esos } \\
\text { supuestos. }\end{array}$ & & \\
\hline $\begin{array}{l}\text { 2. Enfoque } \\
\text { estratégico }\end{array}$ & $\begin{array}{l}\text { Muchas compañías permiten } \\
\text { que los competidores esta- } \\
\text { blezcan los parámetros de su } \\
\text { pensamiento estratégico. }\end{array}$ & $\begin{array}{l}\text { Una empresa debe crear } \\
\text { ventajas competitivas. El ob- } \\
\text { jetivo es derrotar a la com- } \\
\text { petencia }\end{array}$ & $\begin{array}{l}\text { La competencia no es el punto } \\
\text { de referencia. Una empresa } \\
\text { debe perseguir un salto espec- } \\
\text { tacular en el valor para domi- } \\
\text { nar el mercado. }\end{array}$ \\
\hline 3. Clientes & $\begin{array}{l}\text { Los innovadores de valor } \\
\text { creen que la mayor parte de } \\
\text { personas dejarán de lado sus } \\
\text { diferencias, si se les ofrece } \\
\text { un aumento considerable del } \\
\text { valor que se les entrega. }\end{array}$ & $\begin{array}{l}\text { Una empresa debe mantener } \\
\text { y ampliar su base de clientes } \\
\text { por medio de una mayor seg- } \\
\text { mentación y personalización. } \\
\text { Debería centrarse en las di- } \\
\text { ferencias de lo que valoran los } \\
\text { clientes. }\end{array}$ & $\begin{array}{l}\text { Un innovador de valor apunta } \\
\text { a la masa de compradores e in- } \\
\text { cluso permite que algunos } \\
\text { clientes existentes se vayan. Se } \\
\text { centra en los Se centra en los } \\
\text { clientes de mayor valor para la } \\
\text { organización. }\end{array}$ \\
\hline $\begin{array}{l}\text { 4. Activos y } \\
\text { capacidades }\end{array}$ & $\begin{array}{l}\text { Muchas compañías ven las } \\
\text { oportunidades de negocio por } \\
\text { sus activos y capacidades } \\
\text { existentes. }\end{array}$ & $\begin{array}{l}\text { Una empresa debe aprove- } \\
\text { char sus activos y capacida- } \\
\text { des existentes. }\end{array}$ & $\begin{array}{l}\text { Una empresa no debe estar li- } \\
\text { mitada por lo que ya tiene. Se } \\
\text { debe preguntar, ¿qué haríamos } \\
\text { si empezamos de nuevo? }\end{array}$ \\
\hline $\begin{array}{l}\text { 5. Oferta de } \\
\text { productos y } \\
\text { servicios }\end{array}$ & $\begin{array}{l}\text { La competencia convencional } \\
\text { tiene lugar dentro de los lí- } \\
\text { mites claramente estableci- } \\
\text { dos, definido por los produc- } \\
\text { tos y servicios que la indus- } \\
\text { tria tradicionalmente ofrece. }\end{array}$ & $\begin{array}{l}\text { Los límites tradicionales de } \\
\text { una industria determinan los } \\
\text { productos y servicios que } \\
\text { una compañía ofrece. El ob- } \\
\text { jetivo es maximizar el valor } \\
\text { de esas ofertas. }\end{array}$ & $\begin{array}{l}\text { Un innovador de valor piensa } \\
\text { en términos de la solución to- } \\
\text { tal que los clientes buscan, } \\
\text { incluso si eso lleva a la com- } \\
\text { pañía más allá de las ofertas } \\
\text { tradicionales de su industria. }\end{array}$ \\
\hline
\end{tabular}

Fuente: Mauborgne y Chan 1997

La «lógica de la innovación en valor» plantea ir más allá de las reglas que la industria establece. No es motivo de este documento confrontarla con otros planteamientos capitales dentro del desarrollo de la administración estratégica y su pensamiento; se trata de tomar en cuenta las ideas planteadas por Mauborgne y Chan para la generación de valor en las organizaciones actuales.

- El futuro de la competencia: la co-creación de valor con los clientes

Prahalad y Ramaswamy (2004) plantean una revisión de las formas tradicionales de creación de valor, y concluyen que los tiempos actuales de- mandan que las compañías ingresen en la lógica de la «co-creación de valor». Fundamentan este planteamiento en la redefinición del papel de los consumidores. Los autores sostienen que este cambio se construyó sobre los siguientes elementos: 1) Accesibilidad (acceso cada vez mayor a la información por parte de los consumidores), 2) Visión global (pueden obtener información de productos y servicios alrededor del planeta), 3) Conectividad (la alta conexión entre consumidores por el uso altamente difundido de Internet y las redes que surgen de la misma), 4) Experimentación compartida (los consumidores interconectados alrededor del mundo pueden aprender de las experiencias de los demás), y 5) 
Activismo (expresan libremente lo que piensan de las empresas de forma cada vez más activa). Los autores bregan por la inclusión de estos elementos en la gestión de las organizaciones actuales y en sus propuestas de generación de valor.

Sostienen que los consumidores quieren cada vez mayor poder sin asumir responsabilidades. Ellos quieren elegir de forma libre, pero no asumir la responsabilidad de las consecuencias de sus elecciones. El futuro de la relación empresa-consumidor, en términos de funciones, derechos y responsabilidades de ambos, ofrece diferentes predicciones; sin embargo, afirman que las compañías tendrán que implicar a los consumidores en la co-creación de valor. Esto confronta dos hipótesis empresariales profundamente arraigadas: 1) Cualquier compañía o industria puede crear valor unilateralmente; y 2) El valor reside exclusivamente en los productos y servicios de la compañía o industria. Aseveran que la filosofía empresarial tradicional parte de la hipótesis de que la empresa crea valor, que una empresa determina autónomamente el valor que proporcionará por medio de su elección de productos y servicios.

Prahalad y Ramaswamy (2004) asumen que la nueva premisa inicial es que el consumidor y la empresa creen valor conjuntamente. El proceso de obtención de valor se centra en los individuos y en sus experiencias de co-creación. Se debe tener en cuenta la calidad de las experiencias de cocreación de valor, no solo de la calidad de los pro- ductos y los procesos de la empresa. La calidad depende de la infraestructura para la interacción entre empresas y consumidores, orientados en torno a la capacidad para crear una variedad de experiencias. Afirman que en la economía emergente, la competencia se centrará en las experiencias de co-creación personalizadas, resultando en un valor realmente único para cada individuo. El proceso de co-creación de valor se centrará en los siguientes pilares: diálogo, acceso, evaluación del riesgo y transparencia (véase el cuadro 3 ).

Prahalad y Ramaswamy (2004) plantean que la combinación de estos elementos permite a las empresas considerar a los clientes como colaboradores. La transparencia facilita el diálogo de colaboración con los consumidores. La experimentación constante, acompañada del acceso y de la evaluación del riesgo por ambas partes, puede conducir a nuevos modelos empresariales y funcionalidades diseñadas para permitir experiencias de co-creación positivas.

Los autores dan un aporte adicional a la generación de valor porque consideran que los compradores y/o clientes no solo son los adquirientes de los productos o servicios que la empresa ofrece, sino que ellos se tornan en colaboradores de las organizaciones, pues pueden plantear una generación conjunta de valor. El consumidor es escuchado y consultado en este proceso y su opinión puede servir para desarrollar ajustes en la cadena de valor.

\section{Cuadro 3}

\section{Principios de la co-creación de valor}

\begin{tabular}{|c|c|c|c|}
\hline Diálogo & Acceso & Evaluación del riesgo & Transparencia \\
\hline $\begin{array}{l}\text { La interactividad, el compro- } \\
\text { miso y una propensión a ac- } \\
\text { tuar por ambas partes. Impli- } \\
\text { ca llegar a un entendimiento } \\
\text { empático de lo que los consu- } \\
\text { midores experimentan y reco- } \\
\text { nocer el contexto de experien- } \\
\text { cias emocionales, sociales y } \\
\text { culturales. El diálogo crea y } \\
\text { mantiene una comunidad leal. }\end{array}$ & $\begin{array}{l}\text { Cada vez más, el objeti- } \\
\text { vo de los consumidores } \\
\text { es acceder a experien- } \\
\text { cias deseables -no nece- } \\
\text { sariamente a la propie- } \\
\text { dad del producto-. No } \\
\text { hace falta tener algo para } \\
\text { poder tener acceso a una } \\
\text { experiencia. }\end{array}$ & $\begin{array}{l}\text { Aquí, el riesgo se refiere a } \\
\text { la probabilidad de perjudi- } \\
\text { car al consumidor. } \\
\text { Cada vez se habla más del } \\
\text { riesgo y de la relación ries- } \\
\text { gos y beneficios - un deba- } \\
\text { te que el movimiento de la } \\
\text { co-creación de valor va a } \\
\text { intensificar-. }\end{array}$ & $\begin{array}{l}\text { A medida que la in- } \\
\text { formación sobre los } \\
\text { productos, tecnolo- } \\
\text { gías y sistemas em- } \\
\text { presariales va siendo } \\
\text { más accesible, cada } \\
\text { vez es más convin- } \\
\text { cente crear nuevos } \\
\text { niveles de transpa- } \\
\text { rencia. }\end{array}$ \\
\hline
\end{tabular}

Fuente: Prahalad y Ramaswamy 2004 
- La revolución de la contribución de los usuarios

Cook (2008) afirma que los sistemas de contribución del usuario agregan y apalancan los aportes o las conductas de los usuarios, de tal forma que son útiles para otras personas; es decir, para otros consumidores.

Los usuarios pueden ser clientes, empleados, posibles clientes 0 , incluso, personas sin relación previa con la empresa. Sus contribuciones pueden ser activas (trabajo, experticia o información) o pasivas o inconscientes (datos de comportamiento que se recopilan automáticamente durante una transacción o una actividad). Aunque la empresa conserva el control del sistema y podría optar por modificar su diseño, este convierte los aportes en productos útiles en tiempo real con poca o nula intervención de la empresa.
Según Cook (2008), un sistema como este crea valor para una empresa como consecuencia del valor que le entrega a los usuarios, tales como recomendaciones de compras personalizadas, conexiones entre compradores y vendedores de artículos difíciles de encontrar, nuevas relaciones personales o de negocios, precios más bajos, pertenencia a una comunidad, esparcimiento, información de todo tipo.

El autor manifiesta que esta revolución plantea un doble desafío para los administradores. Primero, deben aprender cómo detectar oportunidades para crear valor a partir de las contribuciones de los usuarios. Segundo -y aquí está la parte difícil-, al aprovechar estas oportunidades deben superar la resistencia organizacional que naturalmente surge ante la idea de ceder una cantidad importante de control a personas fuera de la empresa. Estos planteamientos se pueden resumir en el gráfico 3.

\section{Gráfico 3}

\section{La revolución de la contribución de los usuarios}

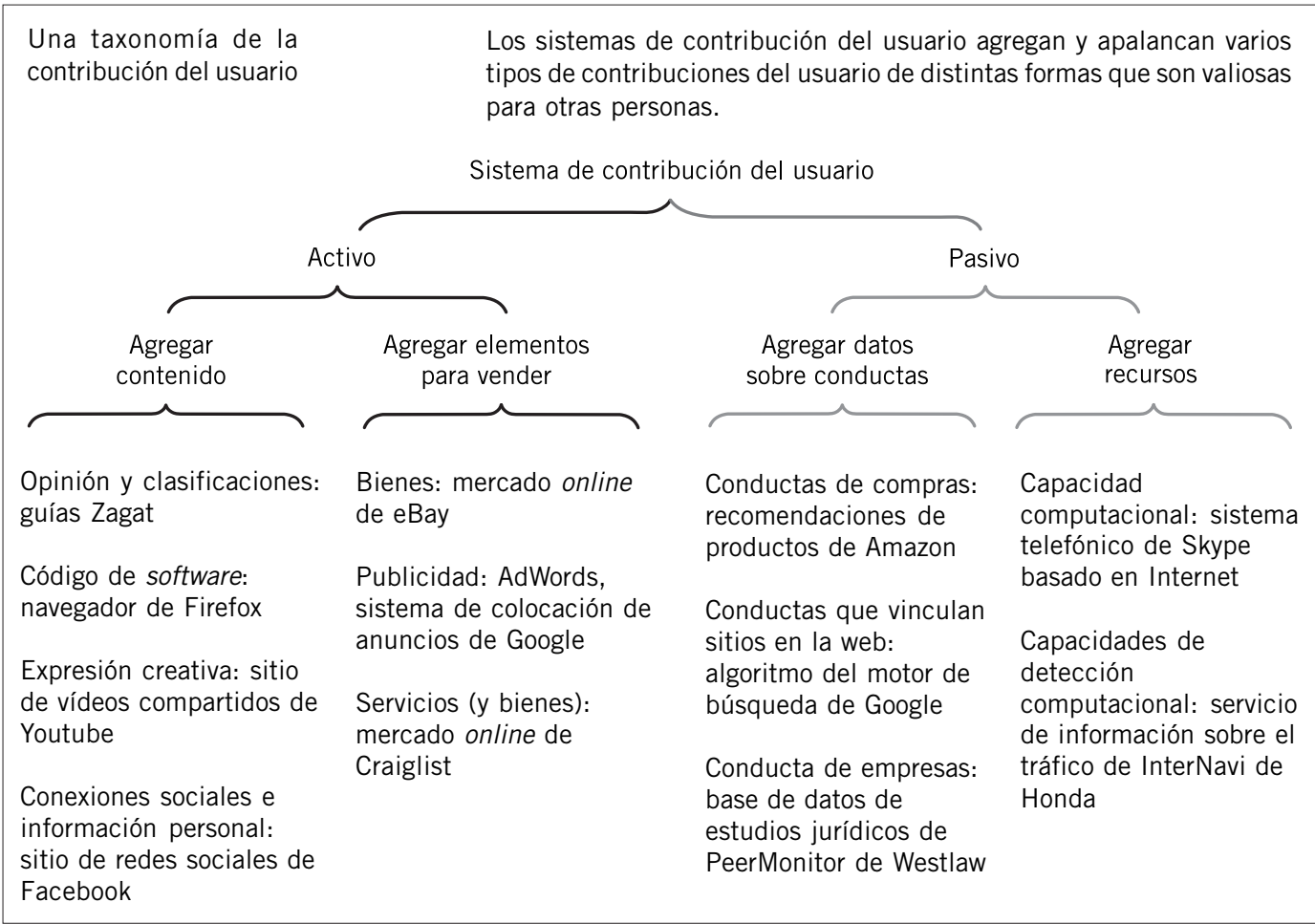

Fuente: Cook 2008 
En la línea de la co-creación de valor, Scott sostiene que la función de "generadores de valor», asumido en los últimos años por los usuarios, consolida un nuevo sistema en el cual se cree que las cadenas de valor de las empresas de manufactura, de servicio -sea de empresas con o sin fines de lucro-, deben evolucionar.

\section{- El proceso del capturador de valor}

McGrath y Keil (2007) proponen el "proceso del capturador de valor», como un elemento clave para las organizaciones, y que tiene como base el desarrollo de proyectos que las organizaciones muchas veces descartan rápidamente con una simple decisión: el emprendimiento "va» 0 "no va». Es decir, es confrontado al mercado o dejado de lado directamente. Los autores plantean un enfoque más profundo, sugiriendo una serie de alternativas para el proyecto antes de desecharlo rotundamente. Aseveran que las empresas eficientes en la generación de valor tratan los emprendimientos relacionados con ello de una forma estratégica y rigurosa, casi como un experimento científico. En ese sentido, en el cuadro 4 se muestran los procesos para una captura de valor más eficiente por parte de las organizaciones.

Según los autores, se puede extraer valor de un emprendimiento que no avanza en su forma original hacia el lanzamiento de un nuevo negocio o que no puede reciclarse para crear una iniciativa nueva y distinta, integrándolo (en un negocio que ya existe), escindiéndolo o rescatando sus destrezas, tecnología, aplicaciones u otros activos, para utilizarlos en otra parte de la empresa.

Se cree que el «proceso del capturador de valor», planteado por McGrath y Keil (2007), puede tomarse en cuenta dentro del diseño de la cadena de valor y de la propuesta que la empresa lanzará al mercado.

\section{Cuadro 4}

Procesos para capturar valor de manera más eficiente

\begin{tabular}{|c|c|}
\hline Proceso & Detalle \\
\hline Fijar los límites estratégicos & $\begin{array}{l}\text { Los líderes de la empresa deben definir claramente el mercado } \\
\text { objetivo y la estrategia de la organización. Es decir, cómo compite. }\end{array}$ \\
\hline $\begin{array}{l}\text { Definir oportunidades aceptables e } \\
\text { inaceptables }\end{array}$ & $\begin{array}{l}\text { Este paso puede reducir el enfoque para los emprendimientos por } \\
\text { desarrollarse. }\end{array}$ \\
\hline $\begin{array}{l}\text { Identificar áreas clave de } \\
\text { oportunidad }\end{array}$ & $\begin{array}{l}\text { Grupos dentro de la organización desarrollan ideas puntuales para } \\
\text { nuevos negocios, las cuales pasan por un proceso de } \\
\text { selección.Puede ser un solo grupo o varios. }\end{array}$ \\
\hline $\begin{array}{l}\text { Crear emprendimientos como } \\
\text { incubadoras temporales }\end{array}$ & $\begin{array}{l}\text { Tomada la decisión de los proyectos o emprendimientos por } \\
\text { desarrollarse, estos deben ser tratados como entidades temporales } \\
\text {-no solo como negocios potenciales-, de manera que se desarrollen } \\
\text { tecnologías, competencias, habilidades, entre otros activos, que } \\
\text { permitan: } \\
\text { - Que los mismos sean adaptados de acuerdo con la } \\
\text { factibilidad del emprendimiento. } \\
\text { - Generar nuevas y mejores formas de identificar la extrac- } \\
\text { ción y generación de valor. }\end{array}$ \\
\hline $\begin{array}{l}\text { Monitorear el progreso con } \\
\text { evaluaciones de hitos }\end{array}$ & $\begin{array}{l}\text { Se trata de una evaluación integral del avance del proyecto sobre } \\
\text { la base de hitos, que involucre a personal de diversas áreas de la } \\
\text { empresa. }\end{array}$ \\
\hline
\end{tabular}

Elaboración propia sobre la base de Gunther y Keil (2007). 
- La reinvención del modelo de negocios

Johnson et al. (2008) afirman que un modelo de negocios consta de cuatro elementos interrelacionados: la propuesta de valor, la fórmula de utilidades, los recursos clave y los procesos clave. Si estos elementos están juntos, crean y entregan valor. Para los autores, el primero de ellos es el más importante (véase el cuadro 5).

Los autores afirman que estos cuatro elementos son los cimientos de cualquier empresa. La propuesta de valor para el cliente y la fórmula de utilidades definen el valor para él mismo y para la propia empresa, respectivamente; los recursos y procesos clave describen cómo ese valor será entregado a los clientes y a la empresa. Los cambios importantes en cualquiera de estos cuatro elementos afectan a los demás y al marco entero. Por esa razón, estos autores plantean que se puede reinventar el modelo de negocios de una organización.
Se cree que en el diseño y análisis de la cadena de valor los aportes presentados, pueden ser elementos relevantes para tomar una decisión estratégica en este ámbito.

Planteamientos por tomarse en cuenta en el análisis de la cadena de valor

El diseño de la cadena de valor es fundamental para conocer la forma en la cual la empresa satisface a sus clientes y Stakeholders involucrados. Sin embargo, no basta solamente con su planteamiento; además, es recomendable desarrollar un análisis de las actividades involucradas. Para esta labor, se puede tomar en cuenta el modelo VRIO y el modelo de los bloques genéricos. Estos dos modelos pueden ser usados para identificar las actividades dentro de la cadena de valor que pueden generar alguna ventaja competitiva para la organización. De esta manera, se puede contar con dos criterios concretos para llegar a un análisis estratégico de la cadena de valor.

\section{Cuadro 5}

Elementos de un modelo de negocios

\begin{tabular}{|l|l|}
\hline \multicolumn{1}{|c|}{ Proceso } & \multicolumn{1}{|c|}{ Detalle } \\
\hline La propuesta de valor para el cliente & $\begin{array}{l}\text { Una empresa exitosa es aquella que descubre la manera de crear } \\
\text { valor para sus clientes; es decir, una forma de ayudar a los clientes } \\
\text { a hacer una tarea que consideran importante. Por «tarea»se } \\
\text { refieren a un problema fundamental en una situación dada que } \\
\text { necesita una solución. }\end{array}$ \\
\hline La fórmula de utilidades & $\begin{array}{l}\text { La fórmula de utilidades es el plan que define cómo la empresa } \\
\text { crea valor para ella misma, mientras brinda valor a los clientes. }\end{array}$ \\
\hline Recursos clave & $\begin{array}{l}\text { Tales como personas, tecnología, productos, instalaciones, } \\
\text { equipamiento, canales y marca requeridos, para brindar la } \\
\text { propuesta de valor al cliente objetivo. Lo fundamental aquí está } \\
\text { en los elementos clave que crean valor para los clientes y la } \\
\text { empresa, y la forma en que esos elementos interactúan. }\end{array}$ \\
\hline Procesos clave & $\begin{array}{l}\text { Las empresas exitosas tienen procesos operacionales y de gestión } \\
\text { que les permiten entregar valor de una manera que pueden repetir } \\
\text { y aumentar a escala. }\end{array}$ \\
\hline
\end{tabular}

Fuente: Johnson et al. 2008: 54-56 
Los autores afirman que estos cuatro elementos son los cimientos de cualquier empresa. La propuesta de valor para el cliente y la fórmula de utilidades definen el valor para él mismo y para la propia empresa, respectivamente; los recursos y procesos clave describen cómo ese valor será entregado a los clientes y a la empresa. Los cambios importantes en cualquiera de estos cuatro elementos afectan a los demás y al marco entero. Por esa razón, estos autores plantean que se puede reinventar el modelo de negocios de una organización.

Se cree que en el diseño y análisis de la cadena de valor los aportes presentados, pueden ser elementos relevantes para tomar una decisión estratégica en este ámbito.

Planteamientos por tomarse en cuenta en el análisis de la cadena de valor

El diseño de la cadena de valor es fundamental para conocer la forma en la cual la empresa satisface a sus clientes y Stakeholders involucrados. Sin embargo, no basta solamente con su planteamiento; además, es recomendable desarrollar un análisis de las actividades involucradas. Para esta labor, se puede tomar en cuenta el modelo VRIO y el modelo de los bloques genéricos. Estos dos modelos pueden ser usados para identificar las actividades dentro de la cadena de valor que pueden generar alguna ventaja competitiva para la organización. De esta manera, se puede contar con dos criterios concretos para llegar a un análisis estratégico de la cadena de valor.

\section{- Modelo VRIO}

Los recursos y capacidades (la forma en las cuales las organizaciones aprovechan sus recursos) que hacen que las empresas sean diferentes, son útiles para el logro de la construcción de una ventaja competitiva y, por ende, para el desarrollo de una estrategia eficiente. Barney y Griffin (1992) plantearon un análisis que es conocido como el modelo VRIO. Se trata de una herramienta para poder determinar el potencial -en términos de ventajas competitivas- de los recursos y las capacidades de las organizaciones. Los recursos y las capacidades que pasan el filtro VRIO (Valioso, Raro, Inimitable y aprovechables por la Organización) pueden ser útiles para el desarrollo de una ventaja competitiva para la empresa.

En el cuadro 6 se explican las características que debe tener un recurso o una capacidad para superar el análisis VRIO. Además, se citan las preguntas que Barney y Griffin (1992) establecieron para viabilizar este análisis.

\section{Cuadro 6}

\section{El Modelo VRIO}

\begin{tabular}{|l|l|l|}
\hline \multicolumn{1}{|c|}{ Condiciones } & \multicolumn{1}{|c|}{ Pregunta de análisis } & Idea que representan \\
\hline Valiosos & $\begin{array}{l}\text { Permiten nuevas oportunidades en } \\
\text { el mercado. }\end{array}$ & $\begin{array}{l}\text { ¿Proporciona valor al cliente y una } \\
\text { ventaja competitiva? }\end{array}$ \\
\hline Raros, únicos o escasos & $\begin{array}{l}\text { Son específicos de la empresa, } \\
\text { difíciles de comprar u obtener en } \\
\text { el mercado. }\end{array}$ & ¿Cuentan con ella otros competidores? \\
\hline Inimitables & $\begin{array}{l}\text { Son difíciles de copiar por la } \\
\text { competencia. }\end{array}$ & ¿Sería costoso para otros imitarla? \\
\hline $\begin{array}{l}\text { Inmersos en la } \\
\text { Organización de la } \\
\text { empresa }\end{array}$ & $\begin{array}{l}\text { La empresa está preparada para } \\
\text { suprovechamiento. }\end{array}$ & $\begin{array}{l}\text { ¿Está la empresa organizada para } \\
\text { explotar recurso? }\end{array}$ \\
\hline
\end{tabular}

Fuente: Barney y Griffin 1992 
Este marco de análisis puede aplicarse también a las actividades de la cadena de valor de la organización. De esta forma, el modelo VRIO puede ser empleado como una herramienta de análisis de la cadena de valor, apuntando a identificar actividades clave para la generación de valor de una institución.

- Modelo de los bloques genéricos

El mantenimiento de una ventaja competitiva requiere que una compañía se concentre de forma decidida en «bloques genéricos» de formación de la misma. Estos son: eficiencia, calidad, innovación y satisfacción al cliente (Gil 2001: 32).

Se trata de cuatro factores básicos en las estrategias que puede implantar cualquier institución, independientemente del sector productivo en el que participe y del bien o servicio que produzca. Se sostiene que estos factores se encuentran muy interrelacionados entre sí, de manera que el desarrollo de uno de ellos puede conducir a la realización de otro.
Para lograr el desarrollo y aplicación de los bloques mencionados, según la estrategia planteada por la organización, se debe trabajar sobre la base de sus habilidades, recursos y capacidades. Se afirma que para alcanzar una ventaja competitiva es indispensable conquistar por lo menos uno de estos cuatro factores (véase el cuadro 7).

Desarrollar los temas de calidad, eficiencia, innovación y satisfacción al cliente podría demandar tratados exclusivos para cada uno de ellos. Se trata de temas amplios y de vital importancia en la gestión actual. No solo en cuanto a temas estratégicos, sino también en lo que respecta a niveles funcionales y tácticos dentro de una entidad administrativa. Sin embargo, a continuación, se desarrollan algunas ideas básicas para la aplicación de los bloques genéricos como elementos para el análisis de las actividades dentro de la cadena de valor y determinar cuáles de ellas pueden ser propensas a generar una ventaja competitiva (véase el cuadro 7).

\section{Gráfico 4}

\section{Los bloques genéricos}

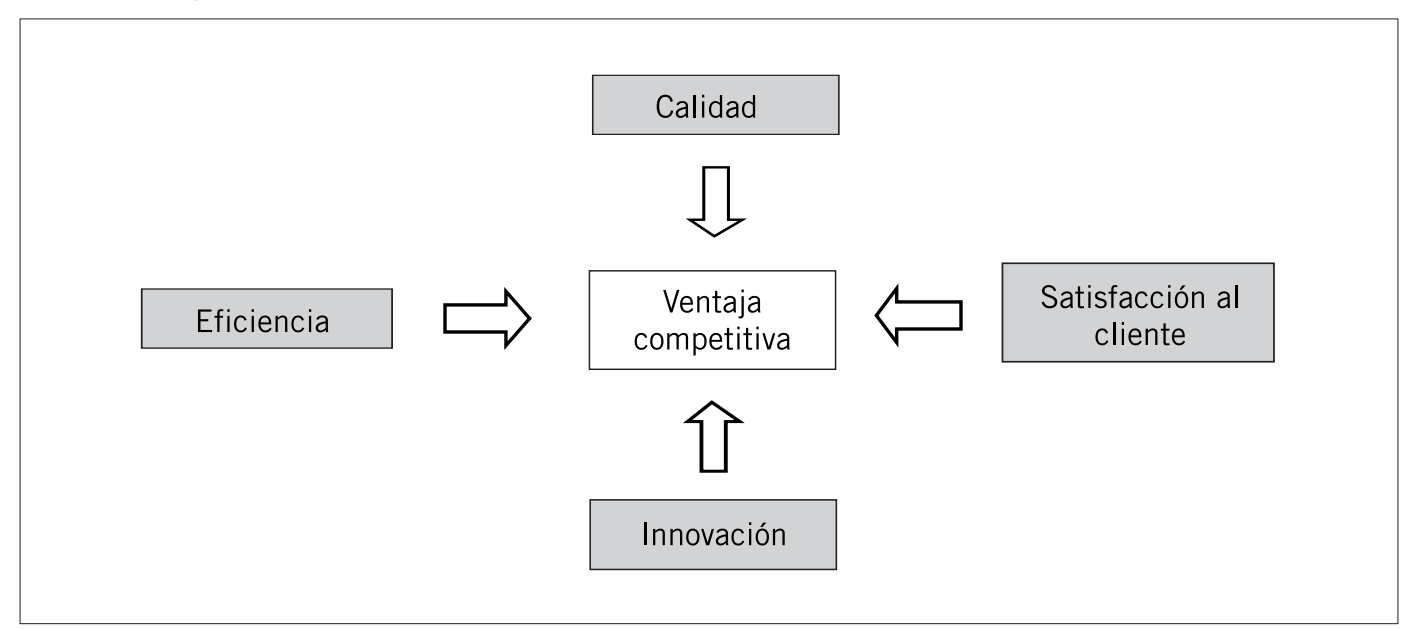

Fuente: Hamilton y Pezo 2005: 19-22 


\section{Cuadro 7}

\section{Los bloques genéricos: ideas referenciales}

\begin{tabular}{|l|l|}
\hline \multicolumn{1}{|c|}{ Bloque genérico } & \multicolumn{1}{c|}{ Algunas ideas referenciales } \\
\hline Eficiencia & $\begin{array}{l}\text { Se refiere al uso idóneo de los recursos de una organización. Esta idoneidad } \\
\text { puede reflejarse en tener los menores costos posibles y lograr los estándares } \\
\text { establecidos por la organización. }\end{array}$ \\
\hline Calidad & $\begin{array}{l}\text { Aunque la definición de calidad puede ser muchas veces poco concreta porque } \\
\text { depende de la percepción del cliente, existen estándares nacionales e } \\
\text { internacionales que pueden ayudar a su definición. Sin embargo, se trata de } \\
\text { un factor relacionado directamente con las características del producto o } \\
\text { servicio que satisfacen a los clientes. }\end{array}$ \\
\hline Innovación & $\begin{array}{l}\text { Este concepto abarca a todos los niveles organizacionales. No solo al desarrollo } \\
\text { de productos nuevos, sino a todo el ámbito organizacional. Se sugiere que los } \\
\text { clientes internos y externos de las organizaciones deben validar las } \\
\text { innovaciones. }\end{array}$ \\
\hline Satisfacción al cliente & Brindar al cliente lo que necesita en el espacio y momento indicado. \\
\hline
\end{tabular}

Elaboración propia sobre la base de Hamilton y Pezo 2005: 19-22.

Tomando en cuenta estos elementos, se puede determinar una ventaja competitiva además de gestionarla, ya que se pueden desarrollar indicadores para cada actividad en función de cada bloque genérico o de la combinación de ellos. Así, los bloques genéricos pueden emplearse para la evaluación de la cadena de valor de una organización, sometiendo las actividades que la conforman a cada uno de ellos.

\section{Evaluación de la cadena de valor}

Pérez-Carballo Veiga (1999: 159-160) afirma que la creación de valor para los accionistas implica lo mismo que para los clientes. Plantea que la evaluación de la cadena de valor comprende: 1) La clara identificación de las actividades que desarrolla una organización; 2) La asignación de sus ingresos, costos y activos a cada una de ellas, 3) La evaluación de la capacidad de crear valor de cada actividad (sugiere que una actividad crea valor cuando el beneficio para el cliente externo o interno que esta genera es superior al costo de Ilevarla a cabo), 3) El análisis de las relaciones entre las actividades para identificar las ayudas mutuas entre ellas, 4) La valoración de las ventajas potenciales de la coordinación de la cadena de valor de la empresa con los clientes y proveedores, y 5) La integración de las cadenas de valor de los diferentes negocios de las organizaciones para reforzar y aprovechar las ventajas de diferenciación y de costos que se presenten.

Con estos planteamientos se puede tener un análisis profundo y estratégico de la cadena de valor de una organización.

Resumen de los aportes en el diseño y análisis de la cadena de valor

Los aportes en la generación de valor en el ámbito organizacional presentados en este texto por el autor, se han agrupado en «básicos para el diseño y comprensión de la generación de valor», «desarrollos por tenerse en cuenta en la adaptación de la cadena de valor para su diseño», «lógicas estratégicas por tomarse en cuenta» y, finalmente, «modelos e ideas por tomarse en cuenta en el análisis de la cadena de valor», tal como se puede apreciar en el cuadro 8. 


\section{Cuadro 8}

\section{Aportes en el diseño y análisis de la cadena de valor}

\begin{tabular}{|c|c|c|}
\hline \multicolumn{2}{|c|}{ Concepto - Planteamiento } & \multirow{2}{*}{$\begin{array}{l}\text { Aportes } \\
\text { - Primer planteamiento formal con respecto a la cadena de valor. } \\
\text { - Acuña específicamente el término cadena de valor. } \\
\text { - Eje seminal de todo lo relacionado con el estudio de la generación } \\
\text { de valor en las organizaciones. } \\
\text { - Planteamiento clave para entender cómo la empresa interactúa } \\
\text { entre sí para la generación de valor. }\end{array}$} \\
\hline $\begin{array}{l}\text { Modelos básicos } \\
\text { para el diseño y } \\
\text { comprensión de la } \\
\text { generación de valor }\end{array}$ & $\begin{array}{l}\text { La cadena de valor de McKinsey } \\
\text { \& Company }\end{array}$ & \\
\hline & $\begin{array}{l}\text { La cadena de valor de Michael } \\
\text { Porter }\end{array}$ & $\begin{array}{l}\text { - Capital en el análisis de la generación de valor de las organiza- } \\
\text { ciones. } \\
\text { - Plantea la distinción entre actividades estratégicas y de apoyo en } \\
\text { la generación de valor de una organización. } \\
\text { - Sugiere el análisis de las interrelaciones entre actividades como } \\
\text { elementos fundamentales para entender la cadena de valor. } \\
\text { - Además, sugiere la determinación de actividades directas, activi- } \\
\text { dades indirectas y actividades de aseguramiento de la calidad. }\end{array}$ \\
\hline \multirow[t]{3}{*}{$\begin{array}{l}\text { Desarrollos por } \\
\text { tenerse en cuenta } \\
\text { en la adaptación - } \\
\text { diseño de la } \\
\text { cadena de valor }\end{array}$} & $\begin{array}{l}\text { La cadena de valor de servicios } \\
\text { de Heskett, Sasser y } \\
\text { Schlesinger }\end{array}$ & $\begin{array}{l}\text { - Plantea que el personal debidamente motivado y comprometido } \\
\text { con los objetivos organizacionales, logra una fuerte fidelidad en } \\
\text { los clientes con los cuales se relaciona. } \\
\text { - Planteamiento trascendental para su inclusión en el diseño de la } \\
\text { cadena de valor para empresas de servicio. }\end{array}$ \\
\hline & $\begin{array}{l}\text { Actualización del modelo de ca- } \\
\text { dena de valor por el propio M. } \\
\text { Porter: Internet y la cadena de } \\
\text { valor }\end{array}$ & $\begin{array}{l}\text { - Plantea las posibilidades que el internet plantea en el proceso de } \\
\text { generación de valor de las organizaciones. }\end{array}$ \\
\hline & La «nueva» cadena de valor & $\begin{array}{l}\text { - Plantea la adaptación de la cadena de valor para empresas que } \\
\text { usan Internet como parte de sus operaciones y sugiere que esta } \\
\text { puede servir para una mayor generación de valor. }\end{array}$ \\
\hline \multirow[t]{4}{*}{$\begin{array}{l}\text { Lógicas } \\
\text { estratégicas por } \\
\text { tomarse en cuenta } \\
\text { en el diseño de la } \\
\text { cadena de valor }\end{array}$} & $\begin{array}{l}\text { La lógica de la innovación de } \\
\text { valor frente a la lógica } \\
\text { convencional }\end{array}$ & $\begin{array}{l}\text { - Confronta el modelo de negocios tradicional con uno basado en la } \\
\text { innovación. } \\
\text { - Sostiene que la empresa debe crear sus propios parámetros de } \\
\text { generación de valor, los cuales pueden escapar a los de la indus- } \\
\text { tria. }\end{array}$ \\
\hline & $\begin{array}{l}\text { El futuro de la competencia: la } \\
\text { co-creación de valor con los } \\
\text { clientes }\end{array}$ & $\begin{array}{l}\text { - Sostiene que los clientes deben desempeñar un papel muy activo } \\
\text { en la generación de valor. } \\
\text { - Plantea que los clientes pueden ser generadores de valor con las } \\
\text { empresas. } \\
\text { - Sugiere una sistematización clara de este proceso de co-creación } \\
\text { de valor. }\end{array}$ \\
\hline & $\begin{array}{l}\text { La revolución de la contribución } \\
\text { de los usuarios }\end{array}$ & $\begin{array}{l}\text { - Refuerza el planteamiento anterior y plantea ideas para su desa- } \\
\text { rrollo. }\end{array}$ \\
\hline & El proceso capturador de valor & $\begin{array}{l}\text { - Plantea el manejo de los proyectos de generación de valor como } \\
\text { iniciativas estratégicas y clave en las organizaciones. } \\
\text { - Sugiere tratar los nuevos proyectos como emprendimientos que } \\
\text { deben ser debidamente incubados. }\end{array}$ \\
\hline
\end{tabular}


Fases para el diseño y análisis de la Cadena de Valor en las organizaciones

\begin{tabular}{|c|c|c|}
\hline \multicolumn{2}{|c|}{ Concepto - Planteamiento } & Aportes \\
\hline \multirow[t]{3}{*}{$\begin{array}{l}\text { Modelos e ideas } \\
\text { por tomarse en } \\
\text { cuenta en el } \\
\text { análisis y la } \\
\text { evaluación de la } \\
\text { cadena de valor }\end{array}$} & Modelo VRIO & $\begin{array}{l}\text { Plantea el análisis VRIO (Valioso, Raro, Inimitable y Organizacionalmente } \\
\text { viable) como herramienta para determinar si un recurso o una capacidad } \\
\text { puede ser fuente de ventaja competitiva. } \\
\text { - Se cree que la misma idea puede ser aplicada a las actividades de la } \\
\text { cadena de valor. }\end{array}$ \\
\hline & $\begin{array}{l}\text { Modelo de los bloques } \\
\text { genéricos }\end{array}$ & $\begin{array}{l}\text { - Sugiere que una ventaja competitiva puede evaluarse sobre la base de } \\
\text { los bloques genéricos (calidad, eficiencia, satisfacción al cliente, e } \\
\text { innovación). } \\
\text { - Se plantea que esta solo se puede obtener por el manejo o dominio de } \\
\text { uno de los bloques mencionados. } \\
\text { - Se cree que los bloques genéricos pueden aplicarse a las actividades } \\
\text { dentro de la cadena de valor de una organización, con el objeto de } \\
\text { conocer cuáles pueden ser fuente de ventaja competitiva. } \\
\text { - Los bloques genéricos pueden servir para el desarrollo de indicadores } \\
\text { y evaluar las actividades de la cadena de valor. }\end{array}$ \\
\hline & $\begin{array}{l}\text { Evaluación de la cadena } \\
\text { de valor }\end{array}$ & $\begin{array}{l}\text { Pérez-Carballo ofrece una serie de elementos que pueden resumir una } \\
\text { adecuada evaluación de la cadena de valor. }\end{array}$ \\
\hline \multicolumn{2}{|c|}{ La reinvención del modelo de negocios } & $\begin{array}{l}\text { Los administradores deben determinar el momento en que su modelo } \\
\text { de negocio y, por ende, su forma de generación de valor puede peligrar } \\
\text { o tornarse obsoleta para redefinirlos. }\end{array}$ \\
\hline
\end{tabular}

Elaboración propia. Recomendaciones: fases propuestas para el di-
seño y análisis de la cadena de valor

La cadena de valor es un modelo fundamental para el entendimiento de la generación de valor, su diseño, análisis y mejora. Hasta este punto, se ha revisado su evolución y se ha planteado una serie de aportes o ideas que mejoran, afinan o hacen repensar la forma en la cual una empresa puede generar valor y todo lo relacionado con ello. Se ha presentado una serie de elementos, de forma que se cuenta con desarrollos que por sí son aportes interesantes e importantes (algunos más que otros, claro está). La revisión de ellos permite contar con «ideas fuerza» que seguidamente se plantearán organizadas en nueve fases para el diseño y análisis de la cadena de valor de una organización, partiendo de los aportes capitales en el tema, y adicionando los aspectos, ideas y conceptos presentados en este documento.

El modelo de la cadena de valor de Porter (1985) es elemental para entender cómo se genera el valor y su análisis respectivo. Por ello, este plan- teamiento es la piedra angular sobre la cual se construye el presente desarrollo. En ese sentido, se respeta decididamente lo que Porter plantea y a esta idea fundamental se le adicionan aportes que el autor de este documento considera relevantes y, además, se sugieren algunas pautas que pueden ayudar en este diseño y análisis de la generación de valor en las organizaciones. Por otro lado, se debe considerar que han pasado aproximadamente 25 años del desarrollo de Porter y aunque su producción se ha mantenido constante y actualizada, los planteamientos presentados pueden complementar su desarrollo en la práctica gerencial, más allá de discusiones teóricas.

En el gráfico 5 se citan los nueve pasos que sirven de marco para las recomendaciones propuestas, las cuales pueden ser el punto de partida para el análisis y diseño de la cadena de valor en una organización. Así como, para el desarrollo de procesos y/o la adición de alguna idea o planteamiento que se considera relevante para la generación de valor dentro de una institución. 


\section{Gráfico 5}

\section{Modelo de fases propuestas para el diseño y análisis de la cadena de valor}

FASE 1: Considerar la necesidad de la adaptación de la cadena de valor.

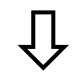

FASE 2: Considerar si la empresa es de manufactura, servicio, un híbrido, orientada a la innovación, con un efecto significativo de la Internet en su desarrollo, entre otros aspectos relevantes.

\section{ฤ}

FASE 3: Diseño de la cadena de valor: determinación de las actividades principales y de apoyo.

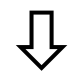

FASE 4: Considerar en el diseño de la cadena de valor los «planteamientos adicionales».

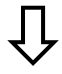

FASE 5: Análisis de la cadena de valor.

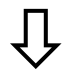

Si bien se plantea que las nueve fases se tomen como consecutivas, el administrador deberá decidir su pertinencia y el orden que se acomode a su realidad empresarial.

FASE 6: Considerar en el análisis de la cadena de valor los «planteamientos adicionales».

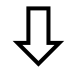

FASE 7: Establecimiento de actividades críticas en la generación de valor de la organización.

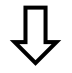

FASE 8: Considerar ideas adicionales para tener una gestión estratégica del diseño y análisis la cadena de valor.

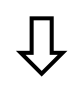

FASE 9: Entender el momento necesario en el cual el modelo de negocios necesita una redefinición.

Elaboración propia.

Estas nueve fases pueden servir para potenciar el diseño y análisis de la generación de valor en las organizaciones. Además, cabe mencionar que éstas surgen no solo de la revisión bibliográfica en el tema, sino de la experiencia del autor en la labor docente, de investigación y de consultoría. A continuación, se presenta una breve explicación de cada una de ellas.

1) Considerar la necesidad de la adaptación de la cadena de valor

Se puede observar que el modelo de Porter en su planteamiento original de 1985 , se adapta perfectamente a una empresa de manufactura. Este autor plantea la cadena de valor como un modelo genérico. En la práctica empresarial, muchas organizaciones lo toman como base y lo adaptan a las operaciones que realizan. En el mismo texto de Porter, se señala que empresas competidoras pueden tener cadenas de valor con diferencias y que de ellas se pueden definir aspectos diferenciadores.

Se cree que la adaptación de la cadena de valor no implica una contradicción ni ataque al modelo porteriano, simplemente se debe 
buscar que esta represente, de la mejor forma posible, la manera en la que la empresa desarrolla la generación de valor.

Resulta importante plantear que la lógica que Porter desarrolló permite apreciar el funcionamiento de una empresa en la realidad, y se cree que ese aspecto es el que posibilita la vigencia de su planteamiento, a pesar del paso del tiempo.

2) Considerar si la empresa es de manufactura, de servicio, es un híbrido, está orientada a la innovación, sufre un efecto significativo de la Internet en su desarrollo, entre otros aspectos relevantes.

Ante el planteamiento inicial de Porter, muchos autores han demostrado su interés de sugerir adaptaciones o versiones particularizadas de la cadena de valor. En este sentido, temiendo una visión muy heterodoxa del tema, se cree que estos desarrollos complementan el aporte primigenio de dicho autor.

De los diversos planteamientos complementarios que existen en la literatura de la administración estratégica, en este documento se presenta una cadena de valor orientada a empresas de servicio, que puede servir para tener un acercamiento y facilitación del diseño y análisis de la misma para empresas de servicio o que necesiten un híbrido para desarrollarse (producir algo y ofrecerlo mediante un servicio). Asimismo, también se ha presentado una cadena de valor para trabajar la innovación dentro de la empresa, la cual puede ser un ingrediente adicional cuando una organización siente que la innovación es un elemento crítico en su preocupación estratégica.

Otro tema muy relevante es la aparición de la Internet en el mundo de los negocios y su, cada vez mayor, importancia en los modelos de negocios de las organizaciones. Para tener alguna referencia de la inclusión de la Internet en el diseño y análisis de la generación de valor, se sugiere tener en cuenta lo que el mismo
Porter (2001) plantea («la cadena de valor en Internet»), además de repensar el modelo tradicional, ya que como Briz y Lazo (2001) lo dicen, se puede hablar de una «nueva» cadena de valor.

Estos son algunos planteamientos de adecuaciones especiales; existen otros relacionados con los ajustes especiales a los negocios internacionales, a la agroindustria, etcétera. Así, se cree que estos diversos planteamientos alimentan y enriquecen el modelo de la cadena de valor original. Se sugiere dejar el criterio y la visualización abierta para las respetivas adaptaciones e inclusiones.

3) Diseño de la cadena de valor: determinación de las actividades principales y de apoyo

Si bien McKinsey planteó la idea primigenia de la cadena de valor, Porter enriquece el modelo mediante la distinción entre las actividades principales y las secundarias dentro de la generación de valor. Esta idea permite tener una mayor claridad en la determinación de las actividades clave para la organización. En su modelo, Porter establece una pauta para decidir qué es principal y qué es de apoyo. Tomando este patrón como referencia, los administradores deben tener el criterio suficiente para -dentro de sus organizaciones- determinar cuáles son actividades principales o estratégicas.

4) Considerar en el diseño de la cadena de valor los «planteamientos adicionales»

Para mejorar el diseño de la cadena de valor, en este estudio se han considerado como «planteamientos adicionales» los trabajos de Mauborgne y Chan (1997), Prahalad y Ramaswamy (2004), Cook (2008) y McGrath y Keil (2007).

Estos desarrollos son relevantes para plantearse el reto del diseño de la cadena de valor; es decir, la forma en que esta será generada por la organización. Queda claro que no se sostiene que estos "planteamientos adicionales» 
sean los únicos existentes o los mejor desarrollados, simplemente se sugiere tenerlos en cuenta en el mencionado diseño. Además, se dejan las puertas abiertas a otros desarrollos, que pueden servir para apuntalar la generación de valor y su entendimiento.

\section{5) Análisis de la cadena de valor}

Luego de diseñar la cadena de valor, se sugiere realizar su análisis. En este análisis se comprenderá la generación de valor y se corroborará y ajustará la definición de actividades estratégicas y de apoyo.

Se sugiere que el análisis de la cadena de valor se desarrolle de manera profunda, para lo cual se revisarán todas las actividades citadas en la cadena. En este análisis, se recomienda:

- Considerar las interrelaciones que existen entre las actividades. Porter plantea que de estas pueden concluirse elementos para la identificación o desarrollo de ventajas competitivas.

- Se puede analizar cada actividad de la cadena empleando el marco VRIO.

- Se puede analizar cada una de las actividades sobre la base de cada uno de los bloques genéricos.

Para una evaluación integral de la cadena de valor, se puede desarrollar los pasos sugeridos por Pérez-Carballo (1999) citados en este trabajo.

6) Considerar en el análisis de la cadena de valor los "planteamientos adicionales»

De forma similar al diseño, en el análisis también se recomienda tener en cuenta los «planteamientos adicionales» mencionados anteriormente. La lógica de la innovación aplicada al modelo de negocios de la empresa y la idea de que el cliente es un co-creador de valor con la empresa, son dos ideas de mucha fuerza que podrían ser relevantes para el diseño y análisis de la generación de valor de una empresa. Esto implica nuevas maneras de visualizar, diseñar y analizar la cadena de valor.

7) Establecimiento de actividades críticas en la generación de valor de la organización

A pesar que ya se definieron las actividades principales y las de apoyo, se cree que luego del análisis de la cadena de valor (los elementos incluidos en el quinto y sexto punto del presente, y todo lo que de ellos se puede derivar), se sugiere establecer, clara y estratégicamente, las actividades fundamentales para la generación de valor dentro de una organización.

Esta determinación es fundamental porque luego de un análisis profundo, es factible afirmar que a partir de estas actividades se puede -0 se debe - construir la ventaja competitiva de la organización.

8) Ideas adicionales para tener una gestión estratégica del diseño y análisis la cadena de valor

Finalmente, para cerrar el modelo, se plantean algunas sugerencias adicionales que pueden ser útiles en el diseño y análisis de la cadena de valor:

- Comparar la cadena de valor con la competencia. Se tienen claro que existe información estratégica a la que no se tendrá acceso. Sin embargo, resultaría provechoso para el desarrollo de la organización poder confrontar el proceso de generación de valor con el que desarrollan los competidores.

- Tener en cuenta las buenas prácticas de la industria nacional e internacional como parámetros de comparación. Existen informes, foros, conferencias y publicaciones en las cuales se puede tener información relevante acerca de la generación de valor en la misma industria, industrias similares o complementarias. Esto puede permitir la generación de ideas nuevas o juicios acerca del rendimiento eficiente de la generación de valor de la organización. 
9) Entender el momento necesario en el cual el modelo de negocios necesita una redefinición Un profundo diseño y análisis de la generación de valor, asumido de forma estratégica y como un proceso serio, puede tener una conclusión fundamental: la redefinición del modelo de negocios y, por lo tanto, la manera en la que la organización genera valor. Se cree que un administrador debería aspirar a poder determinar el momento indicado para dicha variación como insumo estratégico, ampliamente relevante, para el presente y futuro organizacional.

Todo este diseño y análisis se debe alimentar de las conclusiones del análisis externo, el análisis industrial y la investigación de mercados, de forma que se tenga un panorama integral y verdaderamente estratégico. Un esquema de las fases y relaciones entre las propuestas planteadas, se puede observar en el anexo 1.

\section{Conclusiones}

El presente trabajo pretende establecer un acercamiento a la evolución de la generación de valor y de la cadena de valor -herramienta del Management por excelencia, relacionada con dicha generación-, mediante la presentación de planteamientos complementarios, ideas y elementos que pueden facilitar el diseño y análisis de la mencionada cadena en las organizaciones actuales.

Se puede afirmar que el modelo de M. Porter es general y goza de amplia vigencia. Analizar la generación de valor por medio de una serie de actividades consecutivas y relacionadas entre sí, es aplicable a cualquier tipo de organización. En esta línea, la cadena de valor de Porter es un modelo muy útil para representar cómo las organizaciones asumen el reto de generar valor en el ámbito competitivo.

Para los administradores, la cadena de valor es una herramienta que puede resultar fundamental en el diseño, análisis y entendimiento de la generación de valor en las organizaciones. Su uso puede tornarse aun más estratégico, cuando en ella se identifican las actividades fundamentales para el desarrollo del negocio. Es decir, las que sostienen verdaderamente la generación de la ventaja competitiva; aquellas en las cuales reside genuinamente la generación de valor de una organización.

De manera adicional, se cree que la cadena de valor puede acoger otros planteamientos que la pueden llevar a ser más amplia y a tornarse en una herramienta de análisis interno estratégico muy completa. La razón radica en que, luego de Porter, diversos autores de la administración estratégica han formulado planteamientos e ideas, no solo en el tema de generación de valor y en el análisis interno, sino también en la formulación, selección implementación y control de la estrategia. El administrador moderno tiene muchas posibilidades e ideas frente a las cuales debe ser acucioso y analítico. El mismo debe tener mucho criterio para la incorporación en su práctica empresarial de la diversidad de enfoques existentes en la actualidad y su adaptación a las necesidades de la empresa.

Por otro lado, la Internet es un avance tecnológico fundamental de la humanidad que ha removido sus cimientos, y el Management no ha sido ajeno a ello. Es un hecho de que el diseño y análisis de la cadena de valor de las empresas debe considerar el impacto de la red en sus procesos internos, en sus clientes y en los diversos agentes involucrados en la vida organizacional.

Es fundamental darse cuenta de que los cambios en las formas de generación de valor de las organizaciones pueden ocasionar que las empresas redefinan sus modelos de negocios. Un elemento muy importante que se debe tener en cuenta es la consideración del cliente como "co-creador» de valor. Este enfoque es muy importante porque el mismo tiene cada vez más poder y lo ejerce. Así, muchas empresas lo están incorporando como agente generador de valor. Esta inclusión hace que su función cambie e implica muchos retos, entre los cuales, dependiendo del impacto, destaca la redefinición del modelo de negocios de la 
empresa. Lo mismo puede acontecer con el efecto de la Internet en las organizaciones

Sin ánimo de criticar o denostar algún planteamiento, teoría u opinión desarrollada en el ámbito de la generación de valor, de la cadena de valor y de la administración estratégica en general; se sugiere tomar en cuenta otras ideas y planteamientos formulados en campos pragmáticos o académicos de modo que tanto ejecutivos como estudiosos, puedan tener un panorama amplio al momento de diseñar, analizar e implementar sus procesos particulares de generación de valor.
Finalmente, se sostiene que se ha planteado recomendaciones aplicables, sencillas y factibles de considerar en la realidad empresarial, tanto para el diseño como para el análisis de la cadena de valor. Se trata de complementar los enfoques clásicos con elementos que pueden enriquecer su aplicación en la praxis empresarial. Es evidente que esta investigación no pretende ser concluyente. Busca, más bien, abrir las puertas del debate sin ánimo de incomodar a puristas, académicos, empíricos u otros involucrados en el tema de la generación de valor y de la estrategia empresarial, en general. 


\section{Referencias}

BAND, W.

1994 Creación del valor: la clave de la gestión competitiva, diseño e implantación de una estrategia global. Ediciones Díaz de Santos

BARNEY, J. B. y R. GRIFFIN

1992 The Management of Organizations: Strategy, Structure, Behavior. Boston, Estados Unidos: Houghton Mifflin Co.

BRIZ, J. e I. LAZO

2001 Internet y comercio electrónico: características, estrategias, desarrollo y aplicaciones. 2da. Edición. Mundi-Prensa Libros.

COOK, S.

2008 «La revolución de la contribución de los usuarios». En: Harvard Business Review, vol. 86, $\mathrm{N}^{\circ} 10$, pp. 58-59.

CHAN, W. y R. MAUBORGNE

2005 Blue Ocean Strategy: How to Create Uncontested Market Space and Make the Competition Irrelevant. Cambridge, MA: Harvard Business School Press.

2004 «Blue Ocean Strategy». En: Harvard Business Review, octubre, pp. 76-85.

2003 «Tipping Point Leadership». En: Harvard Business Review, vol. 81, N4, pp. 60-69.

2002 «Charting Your Company's Future». En: Harvard Business Review, vol. 80, pp. 7685.

2000 «Knowing a Winning Business Idea When You See One». En: Harvard Business Review, vol. 78, No 5, pp. 129-38.

1999 "Strategy, Value Innovation, and the Knowledge Economy.» En: MIT Sloan Management Review, vol. 40, N³, pp. 4154.

1999 «Creating New Market Space». En: Harvard Business Review, vol. 77, N 1, pp. 83-93.

1998 «Procedural Justice, Strategic Decision Making and the Knowledge Economy». En: Strategic Management Journal, vol. 19, $\mathrm{N}^{\circ}$ 4, pp. 323-341.
DAVID, F.

2008 Conceptos de administración estratégica. $5^{\text {a }}$ ed. México: Pearson Educación.

DRUCKER, P.

1992 Lagerencia. Tareas, responsabilidades y prácticas. Buenos Aires, Argentina: El Ateneo.

FREEMAN, R. E.

1984 Strategic Management: A Stakeholder Approach. Boston: Pittman Press.

FREEMAN, R. E. y D. L. REED

1983 «Stockholders and Stakeholders: A new perspective on Corporate Governance». En: California Management Review, vol. 25, $\mathrm{N}^{\circ}$ 3, pp. 88-106.

GARCÍA V., E.

2008 «Revisión y ajuste de los fundamentos de la ventaja competitiva y de la estrategia de Supermercados Wong para el período 20082010». Trabajo de investigación presentado para optar al Grado Académico de Magíster en Administración. Lima: Universidad del Pacífico, Escuela de Postgrado.

GIL, M.

2001 Empresa virtual de la idea a la acción. Madrid, España: Escuela Superior de Gestión Comercial y Marketing (ESIC).

GOODPASTER, K. E.

1991 "Business ethics and stakeholder analysis». En: Business Ethics Quarterly, vol. 1, No 1 , pp. 53-73.

GRANT, R. M.

1996 Dirección estratégica: conceptos, técnicas y aplicaciones. Madrid: Civitas Ediciones.

GUITART, L.

2005 La ruptura de la cadena de valor como consecuencia de la subcontratación: una investigación cualitativa mediante el estudio de casos. Barcelona: Universitat de Barcelona. 
HAMILTON W., M. y A. PEZO

2005 Instrumentos de gestión de la ciencia, la tecnología y la innovación. Bogotá, Colombia: Convenio Andrés Bello.

HANSEN, M. H y J. BIRKINSHAW

2007 «La cadena de valor de la innovación». En: Harvard Business Review, vol. 85, № 6, pp. 100-110.

HESKETT, J. L.; T. O. JONES, G. W. LOVEMAN, W. E. SASSER y L. SCHLESINGER

1994 "Putting the Service Profit Chain to Work». En: Revista Harvard Business, vol. 72, № 2 , pp. 164-170.

HESKETT, J. L.; W. E. SASSER y L. SCHLESINGER 1997 The Service Profit Chain. Nueva York: Free Press.

HILL, C. W. L. y G. R. JONES

2005 Administración estratégica: un enfoque integrado. Bogotá, Colombia: McGraw-Hill.

HITT, R; D. IRELAND y R. HOSKISSON

2007 Administración estratégica: competitividad y conceptos de globalización. 6ta. ed. México: Thomson.

JOHNSON, G. y K. SCHOLES

2001 Dirección estratégica. 5ta. ed. Madrid: Prentice Hall.

JOHNSON, M. W.; C. M. CHRISTENSEN y H. KAGERMANN

2008 "Cómo reinventar su modelo de negocios». En: Harvard Business Review, vol. 86, № 12 , pp. 53-63.

JURAN, J. M.

1990 Juran y el liderazgo para la calidad: un manual para directivos. Madrid, España: Ediciones Díaz de Santos.

KAPLAN, R. y D. NORTON

2008 Execution premium: integrando la estrategia y las operaciones para lograr ventajas competitivas. Barcelona: Ediciones Deusto.
2002 El tablero de mando integral. Barcelona: Gestión 2000.

MAUBORGNE, R, y W. CHAN

1997 «Value Innovation - The Strategic Logic of High Growth». En: Harvard Business Review, $\mathrm{N}^{\circ} 75, \mathrm{~N}^{\circ} 1$, pp. 102-112.

MANSO, F. J.

2003 Diccionario enciclopédico de estrategia empresarial. Madrid, España: Ediciones Días de Santos.

MCGRATH, R. y T. KEIL

2007 «El proceso capturador de valor: cómo sacar el máximo provecho de sus nuevos emprendimientos de negocios». En: Harvard Business Review, vol. 85, № 5, pp. 104-112.

MINTZBERG, H.; B. AHLSTRAND y J. LAMPEL

1999 Safari a la estrategia. $1^{a}$ ed. Barcelona: Granica.

MINTZBERG, H; J. QUINN y J. VOYER

1997 El proceso estratégico. España: Editorial Pearson Educación.

NAVAS, J. E. y L. A. GUERRAS

1998 La dirección estratégica de la empresa: teoría y aplicaciones. $2^{a}$ ed. España: Civitas Ediciones.

PÉREZ-CARBALLO, J. F.

1999 Compitiendo por crear valor. Madrid, España: Escuela Superior de Gestión Comercial y Marketing (ESIC).

PIL, F. y HOLWEG, M.

2006 «Evolving from Value Chain to Value Grid». En: MIT Sloan Management Review, vol. 47, $\mathrm{N}^{\circ} 4$, pp. 72-79.

PORTER, M.

2008 "The Five Competitive Forces that Shape Strategy». En: Harvard Business Review, vol. 86, No 1, pp. 78-93.

2006 Ventaja competitiva. 5ta. reimpresión. España: Editorial CECSA. 
2005 Estrategia competitiva: técnicas para el análisis de los sectores industriales y de la competencia. $4^{\mathrm{a}}$ ed. España: Editorial CECSA.

2001 «Strategy and the Internet». En: Harvard Business Review, vol. 79, №3, pp. 62-78.

1987 Ventaja competitiva. México: CECSA.

1985 Competitive Advantage. Nueva York: Free Press.

PRAHALAD, C.K. y V. RAMASWAMY

2004 El futuro de la competencia: creación conjunta de valor único con los consumidores. Barcelona: Gestión 2000.

REAL ACADEMIA ESPAÑOLA

2001 Diccionario de la lengua española. $22^{a}$ ed. Disponible en <http://www.rae.es>.

ROBBINS, S. y M. COULTER

2005 Administración. 8 ${ }^{a}$ ed. España: Editorial Pearson Educación.
SAMUELSON, P. A. y W. D. NORDHAUS

1999 Economía. Madrid, España: McGraw-Hill.

SANTOMÁ VICENS, R.

2008 «Aspectos de gestión en la calidad de servicio. Una aplicación del concepto mapping al caso de las cadenas hoteleras en España». Tesis doctoral. Universitat Ramón Llull, Barcelona.

TAPSCOTT, D.

2000 La creación de valor en la economía digital. Argentina: Ediciones Granica S.A.

THOMPSON, A. y A. STRICKLAND

2006 Administración estratégica. 13a ed. McGrawHill. 


\section{Anexo 1}

Modelo de fases propuestas para el diseño y análisis de la generación de valor en las organizaciones

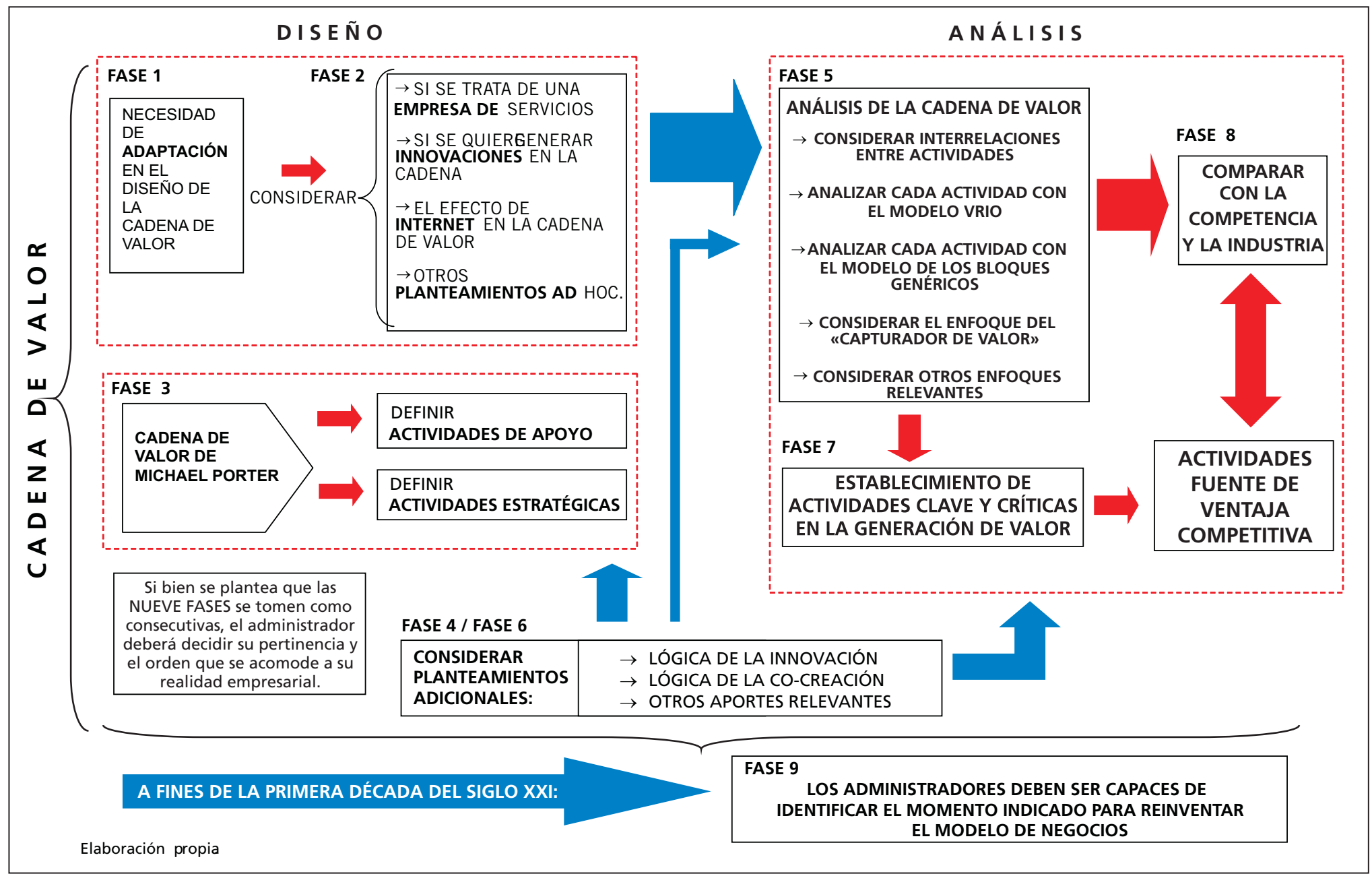

